\title{
Study on the Optimum Steel Slag Content of SMA-13 Asphalt Mixes Based on Road Performance
}

\author{
Wei Chen ${ }^{1}$, Jincheng Wei ${ }^{1,2, *}$, Xizhong $X u^{2}{ }^{2}$, Xiaomeng Zhang ${ }^{2}$, Wenyang Han ${ }^{2}$, Xiangpeng Yan ${ }^{2}$, Guiling Hu ${ }^{1}$ \\ and Zizhao $\mathrm{Lu}^{3}$ \\ 1 School of Transportation Engineering, Shandong Jianzhu University, Jinan 250101, China; \\ chenwei13572468@163.com (W.C.); huguilingtech@Foxmail.com (G.H.) \\ 2 Science and Technology Innovation Center, Shandong Transportation Institute, Jinan 250102, China; \\ xxz137152@163.com (X.X.); zhangxiaomeng@sdjtky.cn (X.Z.); hanwenyang@sdjtky.cn (W.H.); \\ yanxiangpeng336@163.com (X.Y.) \\ 3 Shandong Transportation Planning and Design Research Institute Co., Ltd., Jinan 250031, China; \\ sdjtlzz@163.com \\ * Correspondence: c2523860697@163.com
}

check for updates

Citation: Chen, W.; Wei, J.; Xu, X.; Zhang, X.; Han, W.; Yan, X.; Hu, G.; $\mathrm{Lu}, \mathrm{Z}$. Study on the Optimum Steel Slag Content of SMA-13 Asphalt Mixes Based on Road Performance. Coatings 2021, 11, 1436. https:// doi.org/10.3390/coatings11121436

Academic Editors: Leilei Chen, Ming Liang, Dongyu Niu, Shisong Ren, Ruxin Jing and Valeria Vignali

Received: 26 October 2021 Accepted: 21 November 2021 Published: 23 November 2021

Publisher's Note: MDPI stays neutral with regard to jurisdictional claims in published maps and institutional affiliations.

Copyright: (c) 2021 by the authors. Licensee MDPI, Basel, Switzerland. This article is an open access article distributed under the terms and conditions of the Creative Commons Attribution (CC BY) license (https:// creativecommons.org/licenses/by/ $4.0 /)$.

\begin{abstract}
To reduce the use of aggregates such as limestone and basalt, this paper used steel slag to replace some of the limestone aggregates in the production of SMA-13 asphalt mixes. The optimum content of steel slag in the SMA-13 asphalt mixes was investigated, and the performance of these mixes was evaluated. Five SMA-13 asphalt mixes with varying steel slag content $(0 \%, 25 \%, 50 \%$, $75 \%$, and $100 \%$ ) were designed and prepared experimentally. The high-temperature stability, lowtemperature crack resistance, water stability, dynamic modulus, shear resistance, and volumetric stability of the mixes were investigated using the wheel tracking, Hamburg wheel tracking, threepoint bending, freeze-thaw splitting, dynamic modulus, uniaxial penetration, and asphalt mix expansion tests. The results showed that compared to normal SMA-13 asphalt mixes, the hightemperature stability, water stability, and shear resistance of the SMA-13 asphalt mixes increased and then decreased as the steel slag content increased. All three performance indicators peaked at $75 \%$ steel slag content, and the dynamic stability, freeze-thaw splitting ratio, and uniaxial penetration strength increased by $90.48 \%, 7.39 \%$, and $88.08 \%$, respectively; however, the maximum bending tensile strain, which represents the low-temperature crack resistance of the asphalt mix, decreased by $5.98 \%$. The dynamic modulus of the SMA-13 asphalt mixes increased with increasing steel slag content, but the volume expansion at a $75 \%$ steel slag content was $0.446 \%$ higher than at a $0 \%$ steel slag content. Based on the experimental results, the optimum content of steel slag for SMA-13 asphalt mixes was determined to be $75 \%$.
\end{abstract}

Keywords: different steel slag content; SMA-13 asphalt mixture; pavement performance; optimal steel slag content

\section{Introduction}

With the rapid development of economic globalization, the level of each industry has also increased, and the consumption of steel materials in economic construction is particularly prominent. According to statistics, world crude steel production reached 1808.6 million tons in 2018, with China accounting for more than $50 \%$. Steel slag is a by-product of the steelmaking process, accounting for $13 \%$ of the scrap produced in steelmaking [1]. The utilization rate of steel slag in the United States, Europe, and other developed countries is as high as 70-80\% [2]. However, the utilization rate of steel slag resources in China is only $29.5 \%$, of which $50 \%$ is used for recycling in road works, sintering, iron-making, and steel-making plants. The remaining steel slag resources are disposed of in large-scale open piles or directly in landfills, which not only occupy land resources but also cause severe pollution to the environment [3]. This is contrary to the sustainable 
development goal that many countries are striving to achieve, so the question of how to effectively use steel slag remains $[4,5]$.

Steel slag has better properties, such as roughness and crush resistance, than limestone and basalt [6,7]. Steel slag has abundant metal oxides with rough surfaces due to their aggregation, and the rugged texture of these oxides effectively protects the pyroxene crystals located between them from abrasion and provides a rough and undulating microscopic morphology to the slag surface, causing greater surface friction between steel slag [6].

In recent years, the incorporation of steel slag aggregates into asphalt mixtures has greatly attracted road researchers' interest. The microstructure and surface characteristics of steel slag were analyzed by X-ray diffraction and scanning electron microscopy. The results show that steel slag aggregate has many tiny pores on its surface, which can efficiently adsorb asphalt binder material [7], and the resulting asphalt pavement has higher stability and skid resistance [8-11]. It has been shown that the use of steel slag as coarse aggregate in asphalt concrete pavements can improve the performance of the pavement, especially in terms of durability and stability [1,12-14]. Liapis et al. $[9,15]$ compared paved steel slag asphalt mix sections with conventional limestone asphalt mix pavements and found that the surface macrostructure, as well as the skid resistance of the tested sections, were better. Arbani et al. conducted Marshall tests, dynamic creep tests, and indirect tensile tests on asphalt mixtures incorporated with steel slag to evaluate its mechanical properties and deformation resistance. The results showed that the incorporation of steel slag can effectively improve the Marshall stability and fatigue resistance of asphalt mixes and delay the time of permanent deformation of the mixes. The shortcoming is that the low-temperature crack resistance of steel slag asphalt mixes is lagging [16]. Some researchers have considered grinding steel slag into fine particles and adding it to the hot-mix asphalt mixture in the form of fine aggregates. Test results showed that the steel slag asphalt mixture enhanced the rutting resistance, but the amount of asphalt was significantly increased because of the use of fine steel slag aggregates [5,17]. Kavussi et al. [18] demonstrated the better fatigue resistance of steel slag asphalt mixes by doing four-point bending fatigue tests on steel slag mixes. Chen et al. [19] prepared asphalt mixes by blending gneiss and steel slag aggregates, and they studied the water stability of asphalt mixes by high-temperature damage and low-temperature damage modes. The results indicated that the incorporation of steel slag in asphalt mixes can prevent water damage. Masoudi et al. [20] found that adding steel slag to warm asphalt mixes for aging tests can slow down their short-term and long-term aging. Behnood et al. [21] added steel slag to Stone Mastic Asphalt (SMA) mixes and concluded that the elastic properties of steel slag asphalt mixes were better through performance tests such as Marshall stability and rebound modulus. Phan et al. [22] used infrared camera and microwave heating techniques to analyze the self-healing properties of steel slag asphalt mixes. The results showed that the best ductility and crack self-healing properties were achieved when $30 \%$ of average coarse aggregate was replaced by steel slag. However, there are many irregular protrusions and tiny pores on the surface of steel slag aggregates, which cause asphalt mixes to be difficult to be compacted and have a high void ratio [23], and the pores can absorb large amounts of asphalt, resulting in increased asphalt usage [5]. Another problem is that the chemical composition of the steel slag aggregate contains substances such as free $\mathrm{f}-\mathrm{CaO}$ and $\mathrm{f}-\mathrm{MgO}$ that react with $\mathrm{CO}_{2}$ in the air, mainly to form $\mathrm{CaxMg}_{1}-\mathrm{xCO}_{3}$. If these components are hydrated, they can cause pavement cracking [24]. Therefore, steel slag aggregates should be placed in an open environment or immersed in water for at least six months to allow them to fully react before they are recycled and then made into asphalt mixes [25] for better results. Research has shown that a short-term rutting cycle number of 2520 cycles can simulate heavy traffic volumes, predict long-term rutting, and also reflect the performance of asphalt mixtures; however, the A/C index, complex stability index, and shear index were proven to be reliable indicators to verify the performance of the recycled asphalt mix [26]. Researchers evaluated the effect on rutting resistance and fatigue cracking using 
the locking point concept of aggregates through performance tests of asphalt mixtures, and the concept of interlocking points during compaction of the mix was verified [27].

In summary, mixing steel slag aggregates into asphalt mixes can improve their skid resistance, stability, water damage resistance, self-healing, and rutting resistance. However, there are few studies on the optimal amount of steel slag incorporation for SMA-13 asphalt mixes. In this paper, SMA-13 asphalt mixes prepared with different amounts of steel slag aggregates instead of common limestone coarse aggregates were used and analyzed for road performance and volume expansion. It was concluded that an SMA-13 asphalt mixture with a certain amount of steel slag doping had the best road performance, which provides the theoretical basis for later application and development in practical engineering.

The objectives of this study are: to evaluate the mechanical properties of five types of asphalt mixes with steel slag by means of wheel tracking, Hamburg wheel tracking (HWT), three-point bending, freeze-thaw splitting, dynamic modulus, and uniaxial penetration tests. The purpose is to determine the optimum amount of steel slag for SMA-13 asphalt mixes to provide a theoretical basis for better application to road projects.

\section{Materials and Methods}

\subsection{Materials}

The asphalt binder used in this paper was SBS-modified asphalt produced by JingBo Petrochemical Company (Binzhou, China). According to the Chinese standard JTG E202011 [28], the conventional properties of the asphalt were tested, and the specific technical indices are shown in Table 1, which all meet the requirements of certain specifications.

Table 1. Technical index of SBS modified asphalt.

\begin{tabular}{ccc}
\hline Items & Test Values & Specification [29] \\
\hline Penetration $\left(25^{\circ} \mathrm{C}, 0.1 \mathrm{~mm}\right)$ & 70.1 & $60-80$ \\
Softening point $\left({ }^{\circ} \mathrm{C}\right)$ & 64.5 & $\geq 55$ \\
Flash point $\left({ }^{\circ} \mathrm{C}\right)$ & 272 & $\geq 230$ \\
Ductility $\left(5^{\circ} \mathrm{C}, \mathrm{cm}\right)$ & 46.3 & $\geq 30$ \\
\hline
\end{tabular}

The steel slag was made of hot-sealing steel slag aggregate produced by the Rizhao Iron and Steel Plant in Rizhao, China. To prevent the volume expansion caused by the reaction of steel slag with water, it was placed in a natural environment while exposed to rain and air for eight months, which basically eliminated volume instability. The limestone used was high-quality limestone from Jinan, China. Based on the Chinese standard JTG E42-2005 [30], each functional index of coarse aggregate and fine aggregate was tested, and the specific indices are shown in Tables $2-5$, which met the specification requirements. If steel slag fine aggregate is used for an asphalt mixture, it may cause a larger volume change and an additional increase in the amount of asphalt used [31]. Therefore, in this study, fine limestone aggregate was used as the fine aggregate.

Table 2. Properties of coarse aggregates.

\begin{tabular}{ccccc}
\hline Items & Unit & $\begin{array}{c}\text { Steel Slag } \\
\text { Test Results }\end{array}$ & $\begin{array}{c}\text { Limestone Test } \\
\text { Results }\end{array}$ & $\begin{array}{c}\text { Specification } \\
{[29]}\end{array}$ \\
\hline Apparent relative density & $\mathrm{g} / \mathrm{cm}^{3}$ & 3.543 & 2.726 & $\geq 2.6$ \\
Water absorption & $\%$ & 1.930 & 0.556 & $\leq 2.0$ \\
Crush value & $\%$ & 9.60 & 19.8 & $\leq 26$ \\
Abrasion value & $\%$ & 11.1 & 22.3 & $\leq 28$ \\
Soundness & $\%$ & 2.7 & 6.0 & $\leq 12$ \\
\hline
\end{tabular}


Table 3. Properties of fine aggregates.

\begin{tabular}{cccc}
\hline Items & Unit & Test Values & Specification [29] \\
\hline Apparent relative density & $\mathrm{g} / \mathrm{cm}^{3}$ & 2.725 & $\geq 2.5$ \\
Sand equivalent & $\%$ & 73 & $\geq 60$ \\
Soundness & $\%$ & 15 & $\geq 12$ \\
Angularity & $\mathrm{s}$ & 46 & $\geq 30$ \\
\hline
\end{tabular}

Table 4. Properties of fillers.

\begin{tabular}{cccc}
\hline Items & Unit & Test Values & Specification [29] \\
\hline Apparent relative density & $\mathrm{t} / \mathrm{m}^{3}$ & 2.700 & $\geq 2.50$ \\
Water content & $\%$ & 0.1 & $\leq 1$ \\
Appearance & - & No agglomerates & No agglomerates \\
Hydrophilic coefficient & - & 0.49 & $<1$ \\
Plasticity index & $\%$ & 2.2 & $<1$ \\
\hline
\end{tabular}

Table 5. Steel slag SMA-13 gradation composition design.

\begin{tabular}{|c|c|c|c|c|c|}
\hline & $\begin{array}{c}\text { Steel Slag } \\
\text { Content } 0 \%\end{array}$ & $\begin{array}{c}\text { Steel Slag } \\
\text { Content } 25 \%\end{array}$ & $\begin{array}{c}\text { Steel Slag } \\
\text { Content } 50 \%\end{array}$ & $\begin{array}{c}\text { Steel Slag } \\
\text { Content } 75 \%\end{array}$ & $\begin{array}{c}\text { Steel Slag } \\
\text { Content } \\
100 \%\end{array}$ \\
\hline $\begin{array}{c}\text { Steel slag } \\
10-15 \mathrm{~mm} / \%\end{array}$ & 0 & 11 & 22 & 32 & 40 \\
\hline $\begin{array}{c}\text { Limestone } \\
10-15 \mathrm{~mm} / \%\end{array}$ & 38 & 28 & 18 & 8 & 0 \\
\hline $\begin{array}{c}\text { Steel slag } \\
5-10 \mathrm{~mm} / \%\end{array}$ & 0 & 11 & 22 & 31 & 40 \\
\hline $\begin{array}{l}\text { Limestone } \\
\text { 5-10 mm/\% }\end{array}$ & 39 & 28 & 17 & 9 & 0 \\
\hline $\begin{array}{l}\text { Limestone } \\
0-3 \mathrm{~mm} / \%\end{array}$ & 13 & 12 & 12 & 11 & 11 \\
\hline $\begin{array}{c}\text { mineral } \\
\text { powder } / \%\end{array}$ & 10 & 10 & 9 & 9 & 9 \\
\hline $\begin{array}{l}\text { optimum } \\
\text { asphalt } \\
\text { content } / \%\end{array}$ & $5.14 \%$ & $5.25 \%$ & $5.34 \%$ & $5.50 \%$ & $5.61 \%$ \\
\hline
\end{tabular}

The mineral powder used in this study was made from ground limestone, acting as a filler in the asphalt mix with the aim of reducing the voids in the asphalt concrete. The mineral powder and asphalt together form an asphalt mastic, which improved the strength and stability of the asphalt concrete; the specific indicators are shown in Table 4.

To determine the optimal steel slag incorporation for the SMA-13 asphalt mixes, a total of five mix gradations were designed with different steel slag incorporation levels [32]: $0 \%, 25 \%, 50 \%, 75 \%$, and $100 \%$ steel slag content. The coarse aggregate part of the SMA13 asphalt mixture was formed by combining the steel slag and limestone with particle sizes of $5-10 \mathrm{~mm}$ and $10-15 \mathrm{~mm}$ at certain ratios. The fine aggregate part was limestone with a particle size of $0-3 \mathrm{~mm}$. The volumetric method [33,34] was used to replace the limestone coarse aggregates with steel slag coarse aggregates at different dosing levels while preventing excessive density differences between the two, resulting in deviations between the actual synthetic gradation curve and the target gradation curve. The Marshall compaction test was used to determine the best amount of asphalt. Road performance verification was performed, and the specific grade composition is shown in Table 5. 


\subsection{Experimental Methods}

Performance verification of the SMA-13 asphalt mixes was conducted using the wheel tracking, HWT, three-point bending, freeze-thaw splitting, dynamic modulus, uniaxial penetration, and asphalt mix expansion tests, as shown in Figure 1.
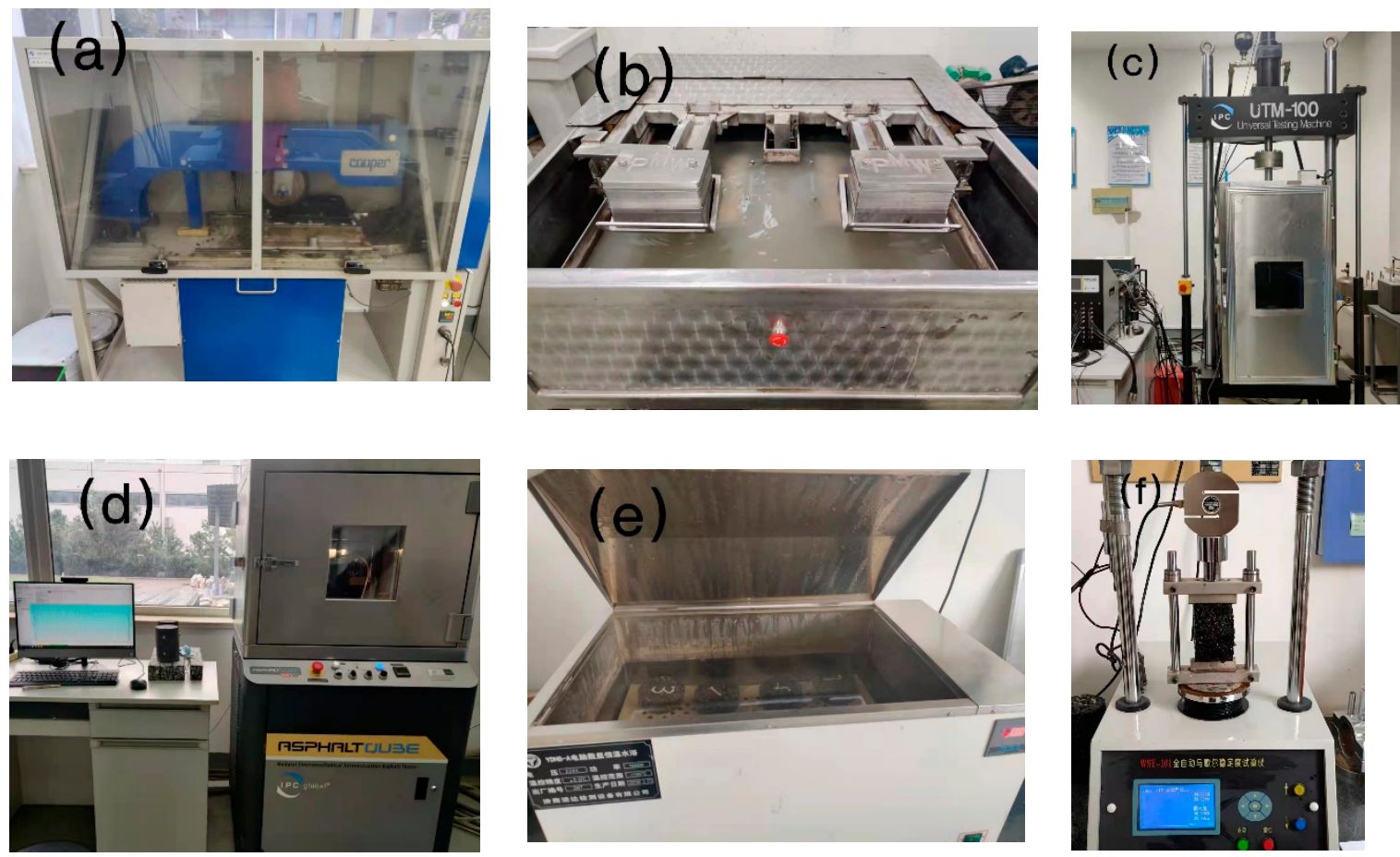

Figure 1. Experimental images of asphalt mixture tests used in this research: (a) wheel tracking test, (b) Hamburg wheel tracking test, (c) three-point bending test, (d) dynamic modulus test, (e) asphalt mix expansion test, and (f) freeze-thaw splitting test.

\subsubsection{Wheel Tracking Test}

The incorporation of steel slag into SMA-13 asphalt mixes usually improves their rutting resistance due to the strength of the slag itself [35]. According to the Chinese standard JTG E20-2011 (T0719) [28], the rutting resistance of asphalt mixture is evaluated by the wheel tracking test, and its dynamic stability can better reflect the ability of asphalt pavement to resist rutting formation under high-temperature conditions in summer. The test used standard asphalt mixture specimens with a length of $300 \mathrm{~mm}$, width of $300 \mathrm{~mm}$, and height of $50 \mathrm{~mm}$. Before the test began, the mixture specimen was placed in a thermostat at $60 \pm 1{ }^{\circ} \mathrm{C}$ for $6 \mathrm{~h}$ to ensure that the internal temperature was stable at $60^{\circ} \mathrm{C}$. Then, the specimen was placed at the test temperature of $60^{\circ} \mathrm{C}$, the contact pressure between a solid tire made of rubber and the specimen was $0.7 \mathrm{MPa}$, and the round-trip crimping speed was $42 \pm 1$ time/min. A linear variable differential transformer (LVDT) collected the rut depth change and calculated the dynamic stability based on the change of time and rut depth, as shown in Equation (1):

$$
D S=\frac{\left(t_{2}-t_{1}\right) \times N}{d_{2}-d_{1}},
$$

where DS is the dynamic stability (cycles/mm); $N$ is the loading peed (42 cycles $/ \mathrm{min}$ ); $d_{1}$ is the amount of deformation corresponding to time $t_{1}(\mathrm{~mm})$; and $d_{2}$ is the amount of deformation corresponding to time $t_{2}(\mathrm{~mm})$. 


\subsubsection{Hamburg Wheel Tracking (HWT) Test}

The HWT test is considered in the literature [36] as a reproducible and reliable method for characterizing the premature failure of asphalt mixtures. According to the standard JTG E20-2011 [28], the HWT test can evaluate the rutting resistance and water stability of asphalt mixtures. Cylindrical specimens of asphalt mixture with a height of $65 \mathrm{~mm}$ and a diameter of $150 \mathrm{~mm}$ formed by a rotary compactor were first cut into Hamburg standard specimens using a cutting machine [37]. Then, we placed a mold where the test piece was installed into $50 \pm 1{ }^{\circ} \mathrm{C}$ water. A steel wheel was made to perform roller compaction on the specimen at a rate of $52 \pm 2$ times per minute. When the steel wheel crushed the specimen 20,000 times or the rutting depth measured by the LVDT reached $12.5 \mathrm{~mm}$, the rutting meter automatically stopped and saved the data. This test was mainly used to determine the early damage of the asphalt mixture by measuring the rutting depth and loading times.

\subsubsection{Freeze-Thaw Splitting Test}

The freeze-thaw splitting test is based on the standard JTG E20-2011 [28]. It evaluates the resistance of asphalt mixtures to water damage by the splitting tensile strength ratio of asphalt mixture specimens before and after freezing and thawing [38]. A standard specimen undergoes Marshall compaction 50 times on each side, and the specimen size is $100 \mathrm{~mm}$ in diameter and $63.5 \pm 2.5 \mathrm{~mm}$ in height. The specimens were divided into two groups; one group was placed in a water bath at $25^{\circ} \mathrm{C}$ for $2 \mathrm{~h} \pm 10 \mathrm{~min}$ before the test, while another group was first placed in a vacuum. The degree of saturation was at $70-80 \%$ before placing the test specimen into a plastic bag filled with $10 \mathrm{~mL}$ of water. Then, the plastic bag was placed in a thermostat at $-18^{\circ} \mathrm{C}$ for at least $16 \mathrm{~h}$, chilled, and then placed in a water bath at $60^{\circ} \mathrm{C}$ for $24 \mathrm{~h}$. Then, the specimens were moved to a water bath at $25^{\circ} \mathrm{C}$ for $2 \mathrm{~h}$, and the splitting strength of the Marshall specimens was measured according to a loading rate of $50 \mathrm{~mm} / \mathrm{min}$.

\subsubsection{Dynamic Modulus Test}

The dynamic modulus test applies an offset sine wave axial compressive stress to the specimen according to a specific temperature and loading frequency to measure the recoverable strain of the specimen, which is an important method to simulate the actual road performance of asphalt mixtures. According to the Chinese standard JTG E20-2011 (T0738) [28], cylindrical specimens of $150 \mathrm{~mm}$ in diameter and $170 \mathrm{~mm}$ in height formed by a rotary compaction apparatus were cut into standard specimens of $100 \mathrm{~mm}$ in diameter and $150 \mathrm{~mm}$ in height by coring. The specimens were held at the test temperature for at least $4 \mathrm{~h}$ before the test. The AST material testing machine was used for testing. The dynamic modulus can be calculated by Equation (2):

$$
\left|E^{*}\right|=\frac{\sigma_{0}}{\varepsilon_{0}},
$$

where $\left|E^{*}\right|$ is the dynamic modulus (MPa), $\sigma_{0}$ is the applied maximum stress (MPa), and $\varepsilon_{0}$ is the measured peak strain.

\subsubsection{Three-Point Bending Test}

The three-point bending test was used to evaluate the performance of asphalt mixtures against bending and tensile damage at low temperatures. According to the Chinese specification JTG E20-2011 (T0715) [28], the asphalt mixture specimen $(300 \mathrm{~mm} \times 300 \mathrm{~mm}$ $\times 50 \mathrm{~mm}$ ) was cut into small, prismatic beam specimens with a length of $250 \pm 2 \mathrm{~mm}$, width of $30 \pm 2 \mathrm{~mm}$, and height of $35 \pm 2 \mathrm{~mm}$. Before the test, the specimens were placed in insulation at $-10 \pm 0.5^{\circ} \mathrm{C}$ for at least $45 \mathrm{~min}$ to ensure that its internal temperature was uniform. Then, the specimen was placed on a base with a span diameter of $200 \mathrm{~mm}$, and a load was applied to the middle of the specimen at a loading speed of $50 \mathrm{~mm} / \mathrm{min}$. The mid-span deflection was measured using the LVDT. To reduce the occurrence of errors, four replicate tests were used for each asphalt mixture, and the flexural tensile 
strength, maximum flexural strain, and bending stiffness modulus were calculated using Equations (3)-(5). The low-temperature durability of the steel slag SMA-13 asphalt mixes was determined by measuring the crack resistance:

$$
\begin{aligned}
R_{B} & =\frac{3 L P_{B}}{2 b h^{2}}, \\
\varepsilon_{B} & =\frac{6 h d}{L^{2}} \\
S_{B} & =\frac{R_{B}}{\varepsilon_{B}}
\end{aligned}
$$

where $R_{B}$ is the flexural tensile strength of the specimen at the time of damage (MPa), $\varepsilon_{B}$ is the maximum bending strain $(\mu \varepsilon), S_{B}$ is the modulus of bending stiffness of the specimen at the time of damage (MPa), $b$ is the width of the span section of the specimen $(\mathrm{mm})$, $h$ is the height of the beam (mm), $L$ is the span of the testing fixture, $200 \mathrm{~mm}, P_{B}$ is the maximum load when the specimen is damaged, and $N$ is the mid-span deflection of the specimen when breaking the ring $(\mathrm{mm})$.

\subsubsection{Uniaxial Penetration Test}

Referring to the Chinese specification JTG D50-2017 [39], a standard cylindrical specimen with a diameter of $150 \mathrm{~mm}$ and a height of $100 \mathrm{~mm}$ was placed in a constanttemperature chamber at $60 \pm 0.5^{\circ} \mathrm{C}$ and insulated for $5-6 \mathrm{~h}$. A UTM-100 tester was used to maintain a loading rate of $1 \mathrm{~mm} / \mathrm{min}$ to apply a $42 \mathrm{~mm}$ diameter loading indenter to the specimen before stopping the test when the stress value dropped to $90 \%$ of the extreme value point. To reduce the occurrence of errors, four replicate tests were used for each asphalt mixture. The penetration strength of the specimen is calculated using Equations (6) and (7):

$$
\begin{gathered}
R_{l}=f_{l} \sigma_{P}, \\
\sigma_{P}=\frac{P}{A},
\end{gathered}
$$

where $R_{l}$ is the penetration strength $(\mathrm{MPa}), \sigma_{P}$ is the penetration stress $(\mathrm{MPa}), P$ is the ultimate load when the specimen is damaged, $\mathrm{N}, A$ is the cross-sectional area of the indenter $\left(\mathrm{mm}^{2}\right)$, and $f_{l}$ is the penetration stress coefficient. When the diameter of the test piece was $150 \mathrm{~mm}, f_{l}=0.35$.

\subsubsection{Asphalt Mix Expansion Test}

According to the Chinese specification JTG E42-2005 [30], when steel slag is used as a material for road asphalt layers, its activity and swelling must be tested to see if it meets the use standards. At least three standard Marshall specimens were made for each steel slag content. The diameters and heights of the specimens were measured with vernier calipers at three and four places, respectively, to calculate the initial volume V1. Then, the specimens were placed into a constant-temperature water bath at $60 \pm 1{ }^{\circ} \mathrm{C}$ for $72 \mathrm{~h}$ before removal and cooling to room temperature. Then, the appearance of cracks or bulging phenomenon were observed, and the new volume of the specimen V2 was measured according to the same method as before. Equation (8) was used to calculate the expansion of the steel slag asphalt mixture:

$$
C=\frac{v_{2}-v_{1}}{v_{1}} \times 100
$$

where $C$ is the expansion amount of the steel slag asphalt mixture (\%), $v_{1}$ is the volume of the specimen before the water bath $\left(\mathrm{cm}^{3}\right)$, and $v_{2}$ is the volume of the specimen after the water bath $\left(\mathrm{cm}^{3}\right)$. 


\section{Results}

\subsection{Study on High-Temperature Stability}

The high-temperature rutting resistance of the SMA-13 asphalt mixes with different steel slag contents was analyzed by the dynamic stability and rutting depth obtained from the wheel tracking and HWT tests with the incorporation of steel slag. Figure 2 shows the variations in dynamic stability and rutting of the asphalt mixes at high-temperature conditions with the increase in steel slag content. The test results showed that the dynamic stability of the mixes increased with the increase in steel slag content, and all samples had a stability that was greater than the specification value of 3000 times/mm [29]. The dynamic stability reached a peak of 8000 times $/ \mathrm{mm}$ when the slag content was $75 \%$ before declining. However, the SMA- 13 asphalt mixes with $25 \%, 50 \%, 75 \%$, and $100 \%$ steel slag were all at least $25 \%$ more dynamically stable than those without steel slag. The rutting depth of the SMA-13 asphalt mixture with $75 \%$ steel slag was $1.19 \mathrm{~mm}$, which was smaller than the other samples. Figure 3 shows that the rutting depth of the HWT test conducted at $50{ }^{\circ} \mathrm{C}$ in a water bath decreased and then increased with the increase in steel slag content, reaching a minimum value of $2.25 \mathrm{~mm}$ when the steel slag content reached $75 \%$. The addition of steel slag can improve the high-temperature rutting resistance of SMA-13 asphalt mixes because steel slag is harder and more angular than limestone, and it has a stronger ability to resist pressure. The compacted coarse aggregate can form a tightly embedded locking structure, and steel slag is alkaline, has more internal pores, and bonds more efficiently with asphalt, thus improving the high-temperature stability of the asphalt mixture. However, as the steel slag content increased to $100 \%$, the amount of asphalt required increased, and the asphalt inside the pores of the slag reached saturation, which is more likely to lead to flooding oil and rutting under the same compaction conditions. As the amount of steel slag content increases, the porosity and compaction may be more difficult to control due to the unique angularity of the slag leading to a more difficult mix structure to be compacted, resulting in reduced high-temperature stability.

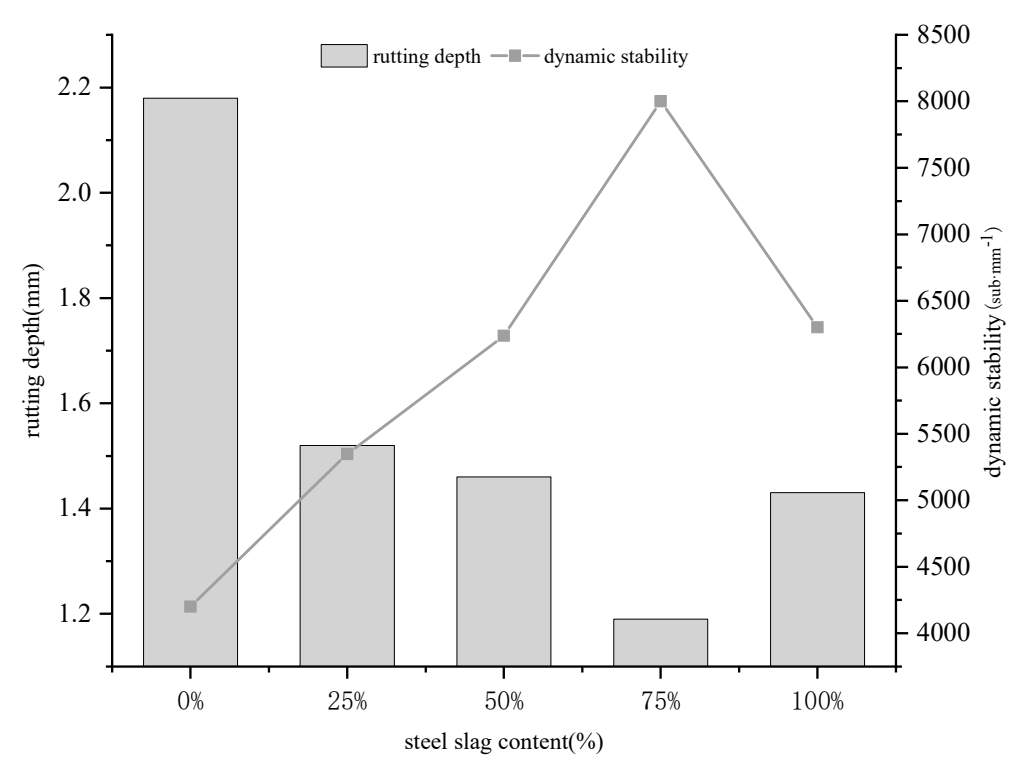

Figure 2. Wheel tracking test results of asphalt mix with different steel slag contents.

\subsection{Study on Low-Temperature Crack Resistance}

The maximum flexural tensile strength and maximum flexural strain of SMA-13 asphalt mixes were analyzed according to the Chinese standard JTG D50-2017 [39] to evaluate their low-temperature crack resistance. Asphalt mixes with good low-temperature crack resistance can be characterized by maximum bending and tensile strains. According to Table 6, the maximum bending and tensile strains of the samples were better than the 
specifications [29]. However, the maximum bending and tensile strains of the SMA-13 asphalt mixture with $0 \%$ steel slag content were the largest. These values started to decrease with the increase in steel slag content, and they decreased by $5.98 \%$ when the steel slag content was $75 \%$. Mainly because of the steel slag in the open storage process, its surface will accumulate many tiny dust particles adsorbed in the pores of the steel slag, reducing the adhesion with asphalt. With the increase in steel slag, the amount of asphalt increases, but the above phenomenon will be more obvious. Therefore, with the increase in steel slag content, the low-temperature crack resistance of the SMA-13 asphalt mixture will decrease. However, when comparing a steel slag content of $75 \%$ and $0 \%$, the low-temperature crack resistance did not decrease much.

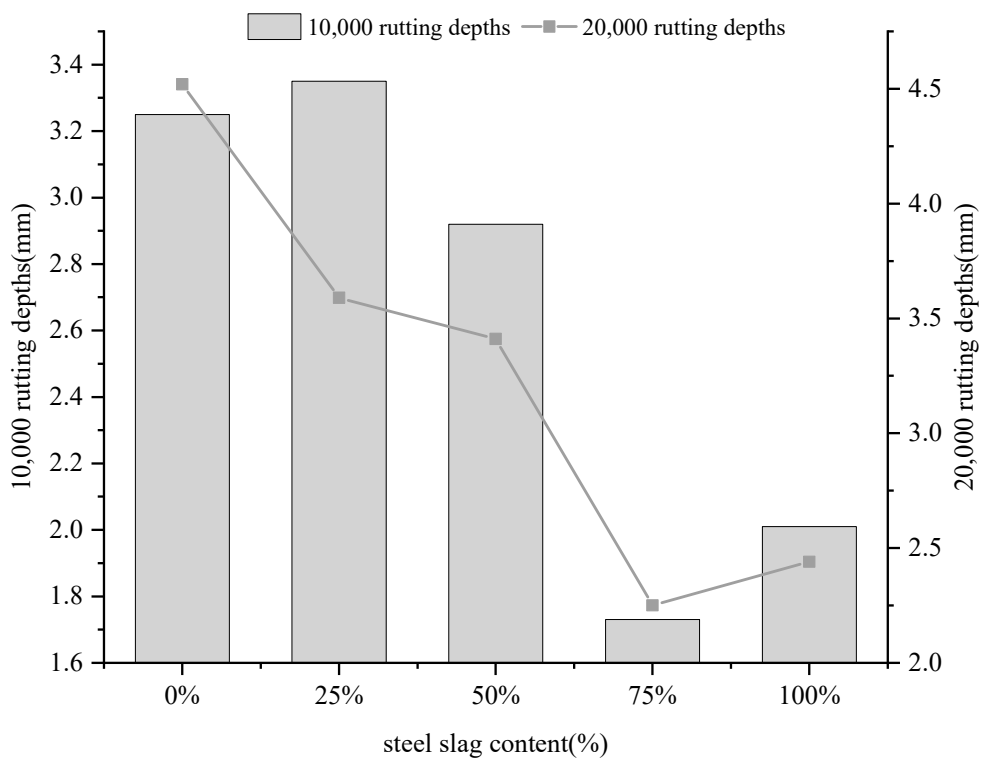

Figure 3. Hamburg wheel tracking test results of asphalt mix with varying steel slag content.

Table 6. Results of low-temperature bending tests on SMA-13 asphalt mixes with varying steel slag content.

\begin{tabular}{cccc}
\hline $\begin{array}{c}\text { Steel Slag Content } \\
(\mathbf{\%})\end{array}$ & $\begin{array}{c}\text { Flexural Tensile } \\
\text { Strength }(\mathbf{M P a})\end{array}$ & $\begin{array}{c}\text { Maximum Bending } \\
\text { Strength }(\boldsymbol{\mu \varepsilon})\end{array}$ & $\begin{array}{c}\text { Bending Stiffness } \\
\text { Modulus }(\mathbf{M P a})\end{array}$ \\
\hline 0 & 16.72 & 3091.74 & 4402.20 \\
25 & 15.04 & 2979.04 & 4563.85 \\
50 & 14.29 & 2925.42 & 4883.31 \\
75 & 13.27 & 2906.60 & 5048.87 \\
100 & 12.55 & 2852.06 & 5408.72 \\
\hline
\end{tabular}

\subsection{Study on Water Stability}

The test conditions of the freeze-thaw splitting test were more stringent than the general water immersion test. The purpose was to test the resistance of the asphalt mixes to water damage while varying the steel slag content. From Figure 4, it can be seen that the freeze-thaw splitting strength ratio of the asphalt mix gradually increased with the incorporation of steel slag, but the increase was not significant. The freeze-thaw splitting strength ratio of the asphalt mixture reached a maximum of $91.5 \%$ when the steel slag content reached $75 \%$, which was $7.39 \%$ higher than that of $0 \%$ slag, followed by a $3.5 \%$ decrease in the freeze-thaw splitting strength ratio when the steel slag content was $100 \%$. This indicated that the incorporation of steel slag can improve the water stability of SMA-13 asphalt mixes. The main reason for this is that there are many tiny pores inside the steel slag, which is also alkaline, and the asphalt combined more densely, Thus, when combined with asphalt, the steel slag can increase the adhesion force and improve the water stability 
of the mixture. However, there are harmful impurities in the steel slag such as $\mathrm{CaO}$ and $\mathrm{MgO}$ that have not fully reacted, and a reaction with water will generate $\mathrm{Ca}(\mathrm{OH})_{2}$ and $\mathrm{Mg}(\mathrm{OH})_{2}$, which affects the water stability of the steel slag SMA-13 asphalt mixture.

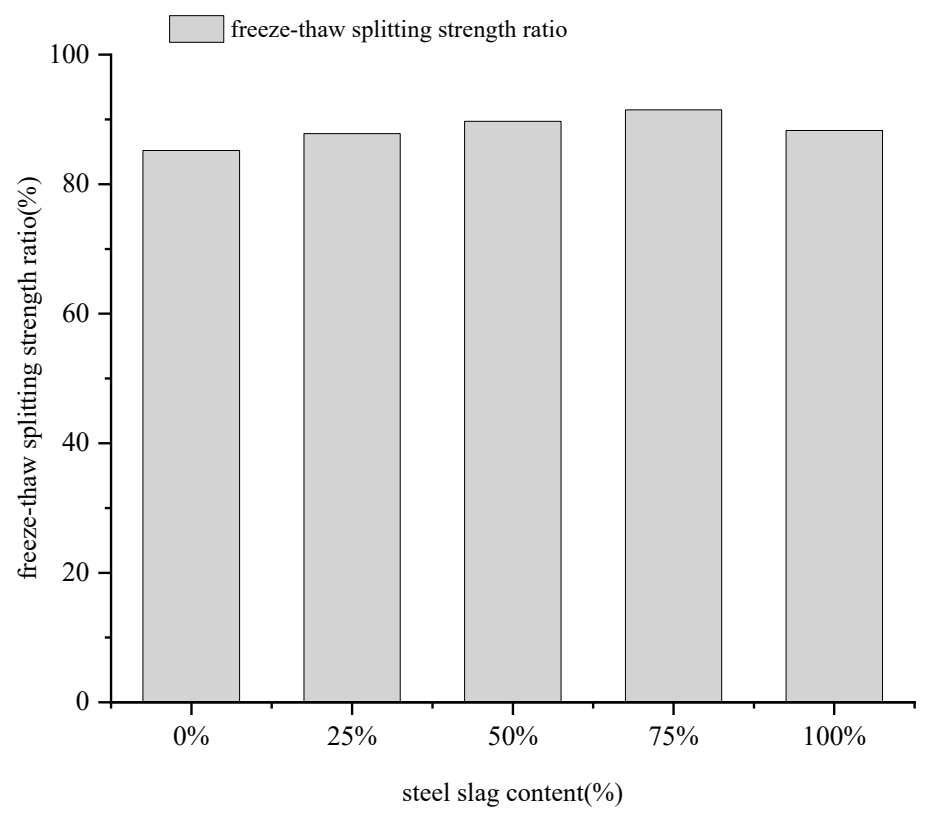

Figure 4. Freeze-thaw splitting strength ratio of SMA-13 under varying steel slag content.

\subsection{Study on Dynamic Modulus}

The main reason for using the uniaxial compression dynamic modulus as an essential performance parameter for asphalt mixture materials is that it is closer to the actual material response characteristics of pavement and to the assumption of an elastic layered system. Figure 5 represents the increase in the dynamic modulus of the asphalt mixture with the increase in loading frequency at a constant test temperature. As the material properties of asphalt mixture are viscoelastic, there is a certain delay in its deformation under the external load stress. Part of the transient energy release is not sufficient, and the accumulation of energy with the increase in loading frequency gradually increases, which also leads to a gradual increase in the dynamic modulus $\left|E^{*}\right|$. The dynamic modulus decreases with increasing temperature when the loading frequency is the same, as was seen in the SMA-13 asphalt mixtures. This showed that the increase in temperature affected the dynamic modulus of steel slag SMA-13 asphalt mixes because the adhesion between the internal pores of steel slag and asphalt decreased when the temperature increased, and the incorporation of steel slag will be accompanied by a higher asphalt dosage. The above phenomenon will be more obvious. According to the Chinese specification JTG D50-2017 [39], the dynamic compression modulus of the designed SMA-13 asphalt mixture measured at $20^{\circ} \mathrm{C}$ and $10 \mathrm{~Hz}$ needs to fall in the range of 7500-12,000 MPa. Therefore, as can be seen from Figure 6, a steel slag content of $0 \%$ and $25 \%$ did not meet the specification requirements. However, the dynamic modulus measured at 50\%, $75 \%$, and $100 \%$ steel slag content met the specification requirements. Therefore, incorporating an appropriate amount of steel slag into SMA-13 asphalt mixes can improve the dynamic modulus values. In summary, it can be seen that the dynamic modulus when the steel slag content was $50 \%, 75 \%$, and $100 \%$ met the specification requirements, where the dynamic modulus was larger at $75 \%$ and $100 \%$. However, the dynamic modulus decreased more rapidly with the increase in temperature when the steel slag content was 100\%. Thus, the recommended amount of steel slag content for SMA-13 asphalt mixes is $75 \%$. 


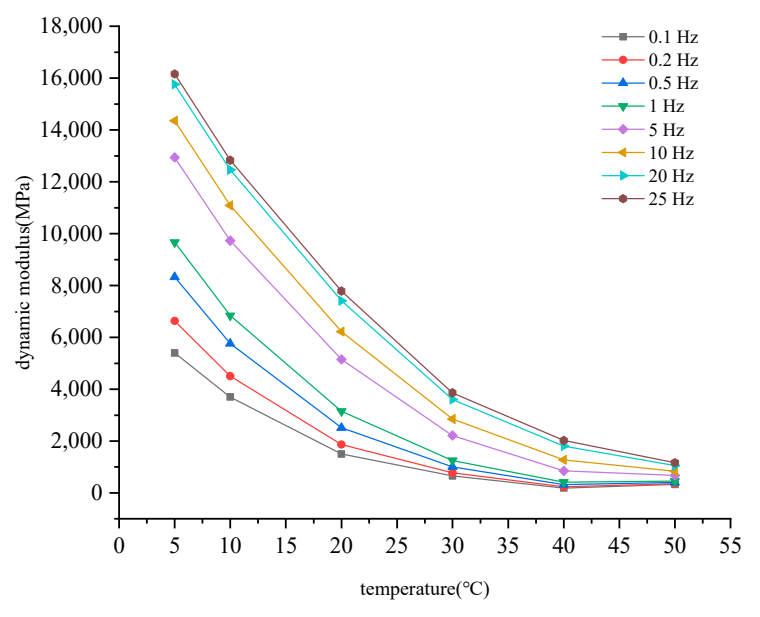

(a)

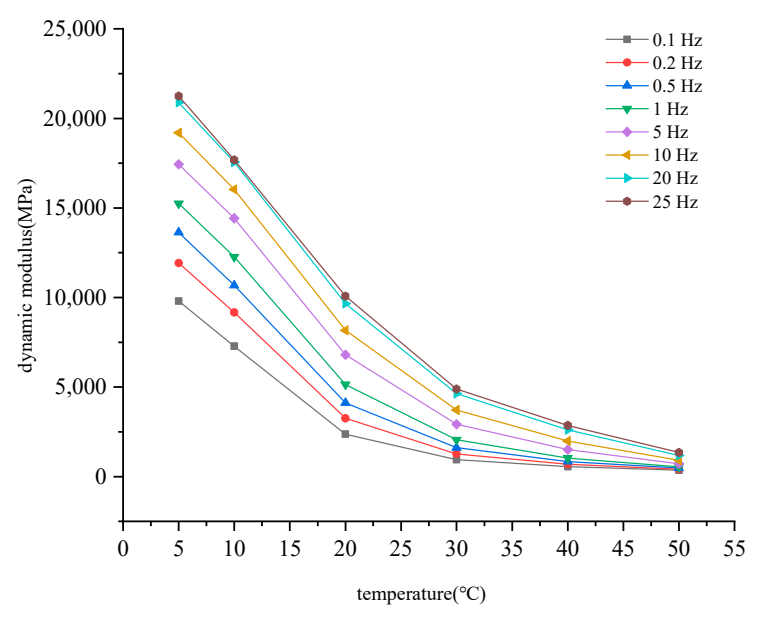

(c)

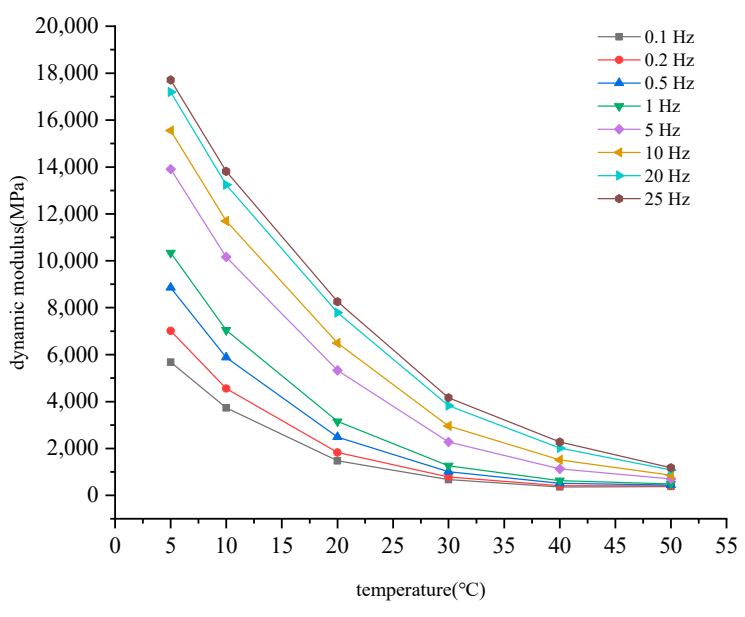

(b)

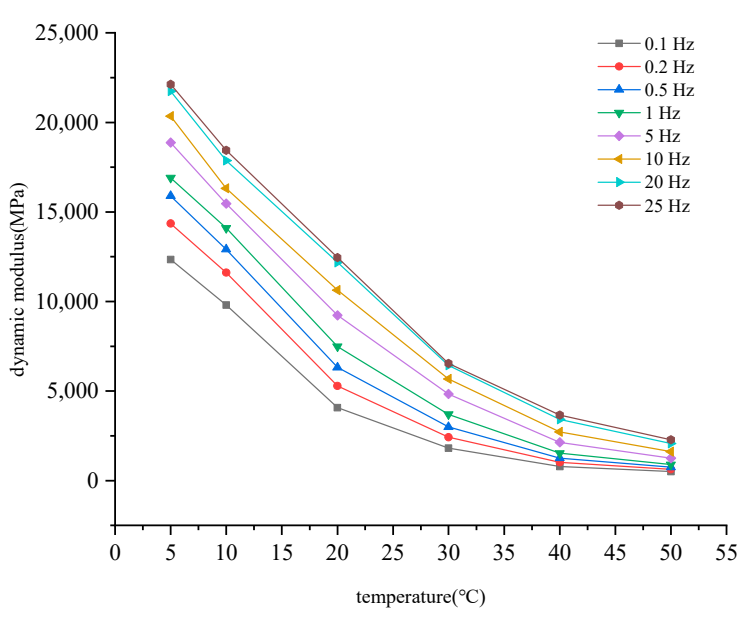

(d)

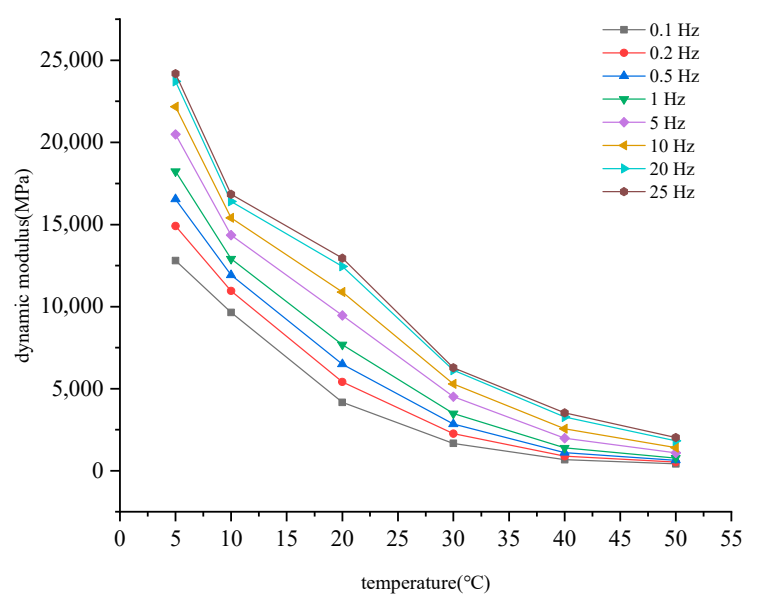

(e)

Figure 5. Dynamic modulus test results of asphalt mixes with varying steel slag content: (a) $0 \%$; (b) $25 \%$; (c) $50 \%$; (d) $75 \%$; and (e) $100 \%$ steel slag content. 


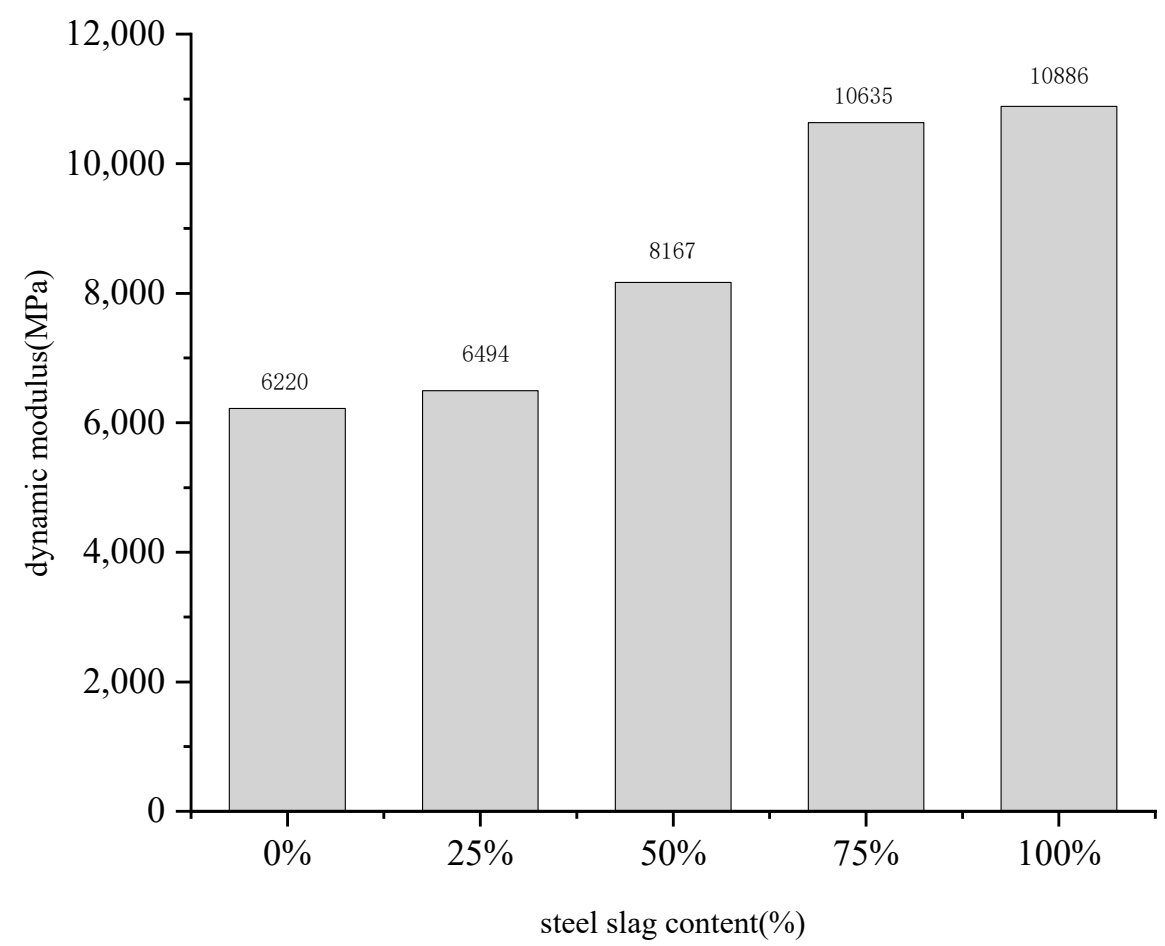

Figure 6. Experimental results on the relationship between dynamic modulus and steel slag content at $20^{\circ} \mathrm{C}$ and $10 \mathrm{~Hz}$.

\subsection{Study on Shear Performance}

Based on the penetration strength calculated from the uniaxial penetration test, the change in shear resistance of the SMA-13 asphalt mixture was analyzed for different amounts of steel slag. The test results are shown in Figure 7. With the increase in steel slag content, the penetration strength of the SMA-13 asphalt mixture first increased and then gradually decreased. The penetration strength of the asphalt mixture reached its peak when the steel slag was mixed at $75 \%$. Steel slag is an alkaline material, and asphalt easily reacts with alkaline materials to form chemical bonds. As a result, the contribution to the shear strength of the mixture is greater, and as the proportion of coarse aggregate in SMA-13 asphalt mixes is increasingly replaced by steel slag, the cohesion increases. Steel slag has irregular angularity, so the inlaid friction force and sliding friction force between steel slag and steel slag is larger than that of limestone aggregates. In addition, the strong locking structure formed by the asphalt mixture after grinding has a greater gain on the internal friction angle; however, when the amount of steel slag exceeds a certain percentage, it will cause the asphalt mixture to be less easily compacted. Furthermore, the sliding friction force between the aggregates will be relatively increased, resulting in a decrease in the internal friction angle. Comprehensive analysis of the shear resistance of the mixture is better when the amount of steel slag is $75 \%$.

\subsection{Study on Volume Stability}

The contents of $\mathrm{f}-\mathrm{CaO}$ and $\mathrm{f}-\mathrm{MgO}$ present in steel slag will increase with the increase in steel slag content, and they will swell to different degrees when mixed with water, which will lead to the appearance of cracks and other diseases in the asphalt mixture [5] and reduce the performance of the road. The asphalt mixture needs to be tested for expansion to check whether its volume expansion rate meets the specification requirements. According to the requirements of Chinese specification JTG E42-2005 [30], the volume change before and after the test is not to be more than $1.5 \%$. The test results are shown in Table 7 . The volumetric expansion of the SMA-13 asphalt mixture increased gradually with the increase in steel slag content. The main reason is that with the increase in steel slag admixture, 
the content of $\mathrm{f}-\mathrm{CaO}$ and $\mathrm{f}-\mathrm{MgO}$ inside the slag also increased and reacted with water to produce $\mathrm{Ca}(\mathrm{OH})_{2}$ and $\mathrm{Mg}(\mathrm{OH})_{2}$ [38], which led to volume expansion and affected the volumetric stability of the asphalt mixture. The volume expansion rate of the SMA-13 asphalt mixtures with varying steel slag content were all less than $0.9 \%$, which met the specification requirements. No cracks on the surface or other undesirable diseases appeared. It may be that the treatment with the steel slag reduced the content of $\mathrm{f}-\mathrm{CaO}$ and $\mathrm{f}-\mathrm{MgO}$ more effectively, and asphalt wrapped around the surface of the steel slag, reducing the chance of contact with moisture, thus reducing the occurrence of swelling. The volumetric stability of the steel slag SMA-13 asphalt mixture is inversely proportional to the amount of steel slag contained in the mixture.

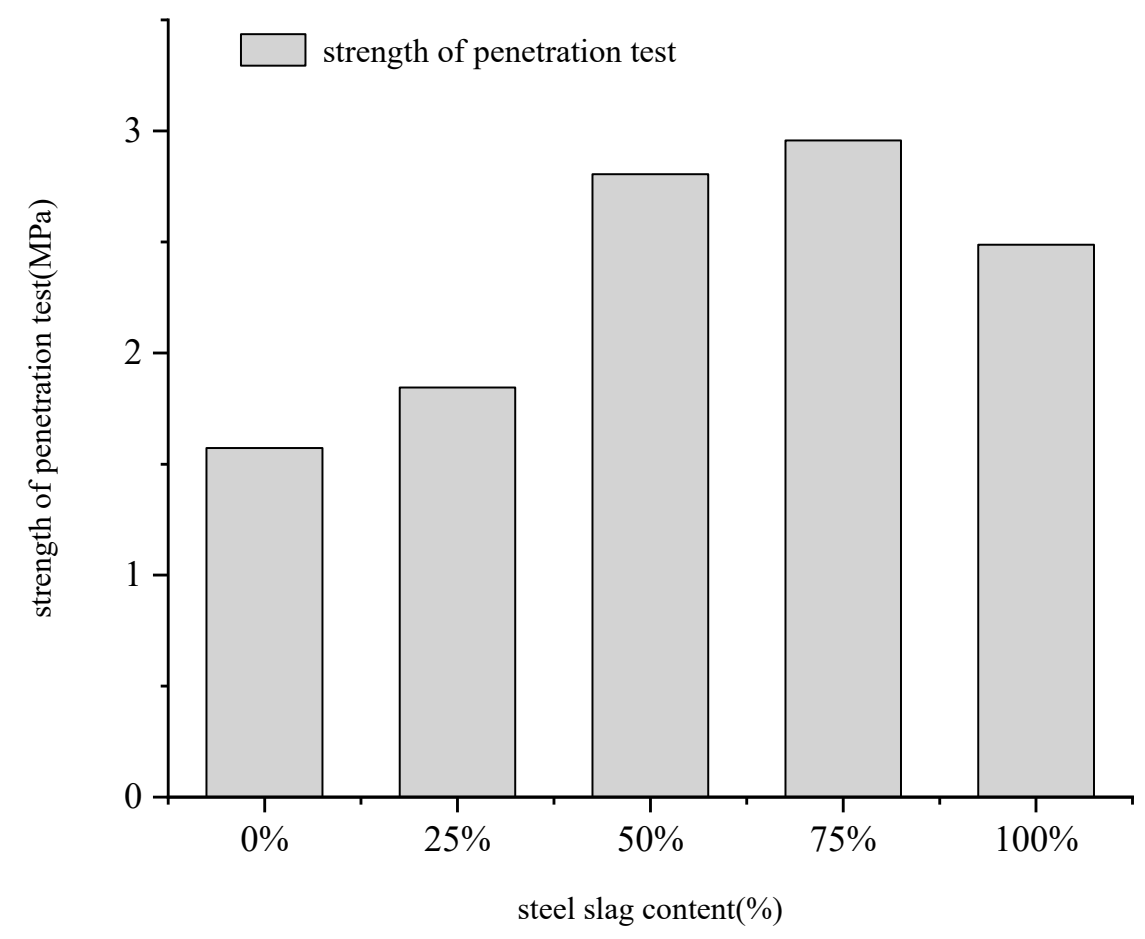

Figure 7. Test results of penetration strength of SMA-13 asphalt mix with different steel slag contents.

Table 7. Results of swelling tests on SMA-13 asphalt mixes with different steel slag contents.

\begin{tabular}{rcccc}
\hline & $\begin{array}{c}\text { Volume before } \\
\left.\text { Immersion } \mathbf{( c m}^{3}\right)\end{array}$ & $\begin{array}{c}\text { Volume after } \\
\text { Immersion } \mathbf{( \mathbf { c m } ^ { 3 } )}\end{array}$ & $\begin{array}{c}\text { Volume Expansion } \\
\text { Ratio (\%) }\end{array}$ & $\begin{array}{c}\text { Surface State of } \\
\text { Specimen after } \\
\text { Immersion }\end{array}$ \\
\hline Steel slag content $0 \%$ & 511.069 & 512.352 & 0.251 & No cracks on the \\
Steel slag content $25 \%$ & 512.123 & 513.931 & 0.353 & surface, no obvious \\
Steel slag content $50 \%$ & 508.177 & 510.347 & 0.427 & drumming \\
Steel slag content $75 \%$ & 508.052 & 511.593 & 0.697 & 0.856 \\
Steel slag content $100 \%$ & 523.717 & 528.200 & & \\
\hline
\end{tabular}

\section{Conclusions}

In this study, the limestone coarse aggregate in SMA-13 asphalt mixes was replaced with steel slag. Five SMA-13 asphalt mixes prepared with varying steel slag content $(0 \%$, $25 \%, 50 \%, 75 \%$, and $100 \%$ ) were tested by the wheel tracking, Hamburg wheel tracking, three-point bending, freeze-thaw splitting, dynamic modulus, uniaxial penetration, and asphalt mix expansion tests to investigate the effect of increasing steel slag content on performance. Based on the results of the various road performance tests, the following conclusions can be drawn. 
(1) Compared to the steel slag content of $0 \%$, the dynamic stability of SMA-13 asphalt mixes with a steel slag content of $25 \%, 50 \%, 75 \%$, and $100 \%$ increased by $27.33 \%, 48.5 \%$, $90.48 \%$, and $50.00 \%$, respectively. When the steel slag content was $75 \%$, the rutting depths for both the wheel tracking test and the Hamburg wheel tracking test reached minimum values of $1.19 \mathrm{~mm}$ and $2.25 \mathrm{~mm}$, respectively. Demonstrating that the incorporation of steel slag can improve the high-temperature stability of SMA-13 asphalt mixes, the best improvement was achieved when the steel slag content was $75 \%$. However, an increased steel slag content can lead to a reduction in the low-temperature crack resistance of the asphalt mix.

(2) The water stability of the asphalt mixes tended to increase and then decrease with the incorporation of steel slag. The freeze-thaw splitting ratio was $91.5 \%$, and the water stability was optimal when the steel slag content was $75 \%$. The presence of hazardous substances in steel slag can lead to poor volumetric stability of the asphalt mix, which decreases with increasing amounts of steel slag.

(3) The dynamic modulus of the asphalt mix increased as the steel slag content increased. At a temperature of $20^{\circ} \mathrm{C}$ and a loading frequency of $10 \mathrm{~Hz}$, the dynamic modulus of the SMA-13 asphalt mixes with 75\% steel slag content increased by $70.98 \%$ compared to those with $0 \%$ steel slag content. The shear resistance of the SMA-13 asphalt mixes was strongly influenced by the embedded effect between the steel slag aggregates. As the slag content increased, the shear resistance tended to increase and then decrease. When the slag content was $75 \%$, the penetration strength of the mix reached a maximum of 2.957 Mpa with an optimal shear resistance.

By analyzing the road performance of SMA-13 asphalt mixes with varying steel slag content, the optimum content was finally determined to be $75 \%$.

Author Contributions: W.C.: Writing-original draft; X.Z., W.C.: Data curation; X.X., W.H., Z.L. and G.H.: Methodology; W.H., X.X., Z.L. and G.H.: Project administration; X.Y., J.W. and X.Z.: investigation; X.Y. and J.W.: Supervision. All authors have read and agreed to the published version of the manuscript.

Funding: This research was funded by National Key R\&D Program of China, grant number (2018YFB1600100), Shandong Natural Science Foundation Committee (ZR2020QE271, ZR2020KE024) and Shandong Province Key R\&D Program (2019GSF109020, 2019GGX101042).

Institutional Review Board Statement: Not applicable.

Informed Consent Statement: Not applicable.

Data Availability Statement: Data sharing is not applicable to this article.

Acknowledgments: The authors would like to thank the Shandong Transportation Institute for their support.

Conflicts of Interest: The authors declare no conflict of interest.

\section{References}

1. Ahmedzade, P.; Sengoz, B. Evaluation of steel slag coarse aggregate in hot mix asphalt concrete. J. Hazard. Mater. 2009, 165, 300-305. [CrossRef]

2. Yi, H.; Xu, G.P.; Cheng, H.G.; Wang, J.S.; Wan, Y.F.; Chen, H. An overview of utilization of steel slag. In Proceedings of the 7th International Conference on Waste Management and Technology (ICWMT), Beijing, China, 5-7 September 2012 ; pp. 791-801.

3. Guo, J.L.; Bao, Y.P.; Wang, M. Steel slag in China: Treatment, recycling, and management. Waste Manag. 2018, 78, 318-330. [CrossRef]

4. Nejad, F.M.; Azarhoosh, A.R.; Hamedi, G.H. The effects of using recycled concrete on fatigue behavior of hot mix asphalt. J. Civ. Eng. Manag. 2013, 19, S61-S68. [CrossRef]

5. Kavussi, A.; Qazizadeh, M.J. Fatigue characterization of asphalt mixes containing electric arc furnace (EAF) steel slag subjected to long term aging. Constr. Build. Mater. 2014, 72, 158-166. [CrossRef]

6. Woodward, W.; Phillips, E.; Sinhal, W.; Woodward, D. The effect of aggregate type and size on the performance of thin surfacing materials. Saferroads Org 2008, 32, 65-71.

7. Wu, S.; Xue, Y.; Ye, Q.; Chen, Y. Utilization of steel slag as aggregates for stone mastic asphalt (SMA) mixtures. Build. Environ. 2007, 42, 2580-2585. [CrossRef] 
8. Mladenovič, A.; Turk, J.; Kovač, J.; Mauko, A.; Cotič, Z. Environmental evaluation of two scenarios for the selection ofmaterials for asphalt wearing courses. J. Clean. Prod. 2015, 87, 683-691. [CrossRef]

9. Liapis, I.; Likoydis, S. Use of Electric Arc Furnace Slag in Thin Skid-Resistant Surfacing. Procedia- Soc. Behav. Sci. 2012, 48, 907-918. [CrossRef]

10. Mladenovic, A.; Sofilic, T.; Sofilic, U. Defining of EAF steel slag application possibilities in asphalt mixture production/Elk plieno slako panaudojimo gaminant asfalto misini galimybes. J. Environ. Eng. Landsc. Manag. 2011, 19, 148-157.

11. Kehagia, F. Skid resistance performance of asphalt wearing courses with electric arc furnace slag aggregates. Waste Manag. Res. J. Int. Solid Wastes Public Clean. Assoc. Iswa 2009, 27, 288-294. [CrossRef] [PubMed]

12. Zhu, J.; Wu, S.; Zhong, J.; Wang, D. Investigation of asphalt mixture containing demolition waste obtained from earthquakedamaged buildings. Constr. Build. Mater. 2012, 29, 466-475. [CrossRef]

13. Setién, J.; Hernández, D.; González, J.J. Characterization of ladle furnace basic slag for use as a construction material. Constr. Build. Mater. 2009, 23, 1788-1794. [CrossRef]

14. Xie, J.; Wu, S.; Lin, J.; Cai, J.; Chen, Z.; Wei, W. Recycling of basic oxygen furnace slag in asphalt mixture: Material characterization \& moisture damage investigation. Constr. Build. Mater. 2012, 36, 467-474.

15. Wen, H.; Wu, S.; Bhusal, S. Performance Evaluation of Asphalt Mixes Containing Steel Slag Aggregate as a Measure to Resist Studded Tire Wear. J. Mater. Civ. Eng. 2016, 28, 04015191. [CrossRef]

16. Arabani, M.; Azarhoosh, A.R. The effect of recycled concrete aggregate and steel slag on the dynamic properties of asphalt mixtures. Constr. Build. Mater. 2012, 35, 1-7. [CrossRef]

17. Ameri, M.; Hesami, S.; Goli, H. Laboratory evaluation of warm mix asphalt mixtures containing electric arc furnace (EAF) steel slag. Constr. Build. Mater. 2013, 49, 611-617. [CrossRef]

18. Kavussi, A.; Jalili, Q.M.; Hassani, A. Fatigue behavior analysis of asphalt mixes containing electric arc furnace (EAF) steel slag. J. Rehabil. Civ. Eng. 2015, 3, 74-86.

19. Chen, Z.; Jiao, Y.; Wu, S.; Tu, F. Moisture-induced damage resistance of asphalt mixture entirely composed of gneiss and steel slag. Constr. Build. Mater. 2018, 177, 332-341. [CrossRef]

20. Masoudi, S.; Abtahi, S.M.; Goli, A. Evaluation of electric arc furnace steel slag coarse aggregate in warm mix asphalt subjected to long-term aging. Constr. Build. Mater. 2017, 135, 260-266. [CrossRef]

21. Behnood, A.; Ameri, M. Experimental investigation of stone matrix asphalt mixtures containing steel slag. Sci. Iran. 2012, 19, 1214-1219. [CrossRef]

22. Phan, T.M.; Park, D.W.; Le, T.H.M. Crack healing performance of hot mix asphalt containing steel slag by microwaves heating. Constr. Build. Mater. 2018, 180, 503-511. [CrossRef]

23. Pasetto, M.; Baldo, N. Performance comparative analysis of stone mastic asphalts with electric arc furnace steel slag: A laboratory evaluation. Mater. Struct. 2012, 45, 411-424. [CrossRef]

24. Chen, Z.; Wu, S.; Wen, J.; Zhao, M.; Yi, M.; Wan, J. Utilization of gneiss coarse aggregate and steel slag fine aggregate in asphalt mixture. Constr. Build. Mater. 2015, 93, 911-918. [CrossRef]

25. Alnadish, A.; Aman, Y. A study on the economic using of steel slag aggregate in asphalt mixtures reinforced by aramid fiber. ARPN J. Eng. Appl. Sci. 2018, 13, 276-292.

26. Javilla, B.; Fang, H.; Mo, L.; Shu, B.; Wu, S. Test evaluation of rutting performance indicators of asphalt mixtures. Constr. Build. Mater. 2017, 155, 1215-1223. [CrossRef]

27. Polaczyk, P.; Ma, Y.; Xiao, R.; Hu, W.; Jiang, X.; Huang, B. Characterization of aggregate interlocking in hot mix asphalt by mechanistic performance tests. Road Mater. Pavement Des. 2021, 22, S498-S513. [CrossRef]

28. JTG E20-2011. Standard Test Methods of Bitumen and Bituminous Mixtures for Highway Engineering; Ministry of Transport, PR China: Beijing, China, 2011.

29. JTG F40-2004. Technical Specifications for Construction of Highway Asphalt Pavenments; Ministry of Transport, PR China: Beijing, China, 2004.

30. JTG E42-2005. Standard Test Methods of Aggregate for Highway Engineering; Ministry of Transport, PR China: Beijing, China, 2005.

31. Xue, Y.; Wu, S.; Hou, H.; Jin, Z. Experimental investigation of basic oxygen furnace slag used as aggregate in asphalt mixture. J. Hazard. Mater. 2006, 138, 261-268. [CrossRef]

32. Asi, I.M.; Qasrawi, H.Y.; Shalabi, F.I. Use of steel slag aggregate in asphalt concrete mixes. Can. J. Civ. Eng. 2007, 34, 902-911. [CrossRef]

33. Gao, J.; Sha, A.; Wang, Z.; Tong, Z.; Liu, Z. Utilization of steel slag as aggregate in asphalt mixtures for microwave deicing. J. Clean. Prod. 2017, 152, 429-442. [CrossRef]

34. Tataranni, P.; Sangiorgi, C. Synthetic Aggregates for the Production of Innovative Low Impact Porous Layers for Urban Pavements. Infrastructures 2019, 4, 48. [CrossRef]

35. Pasetto, M.; Baldo, N. Mix design and performance analysis of asphalt concretes with electric arc furnace slag. Constr. Build. Mater. 2011, 25, 3458-3468. [CrossRef]

36. Chaturabong, P.; Bahia, H.U. Mechanisms of asphalt mixture rutting in the dry Hamburg Wheel Tracking test and the potential to be alternative test in measuring rutting resistance. Constr. Build. Mater. 2017, 146, 175-182. [CrossRef]

37. The Hamburg rutting test-Effects of HMA sample sitting time and test temperature variation. Constr. Build. Mater. 2016, 108, 22-28. [CrossRef] 
38. Wang, W.; Cheng, Y.; Ma, G.; Tan, G.; Sun, X. Further Investigation on Damage Model of Eco-Friendly Basalt Fiber Modified Asphalt Mixture under Freeze-Thaw Cycles. Appl. Sci. 2018, 9, 60. [CrossRef]

39. JTG D50-2017. Specifications for Design of Highway Asphalt Pavenment; Ministry of Transport, PR China: Beijing, China, 2017. 